\title{
Naproxen in rheumatoid arthritis
}

\section{Extended trial}

A. G. MOWAT, * B. M. ANSELL, $\dagger$ J. M. GUMPEL $\ddagger$ H. F. H. HILL, $\S$ A. G. S. HILL, $\S \stackrel{\S}{\circ}$ AND M. STOPPARD **

From the Rheumatology Unit, Nuffield Orthopaedic Centre, Oxford;* Canadian Red Cross Memorial Hospital, Taplow; $\dagger$ Northwick Park Hospital, Harrow; $\ddagger$ Rheumatism Research Centre, Stoke Mandeville Hospital; $\S$ and Syntex Pharmaceuticals, Maidenhead**

\begin{abstract}
Mowat, A. G., Ansell, B. M., Gumpel, J. M., Hill, H. F. H., Hill, A. G. S., and Stoppard, M. (1976). Annals of the Rheumatic Diseases, 35, 498-501. Naproxen in rheumatoid arthritis. Extended trial. 121 patients with active rheumatoid arthritis, 91 of whom had proved intolerant of other nonsteroidal anti-inflammatory agents, were treated for a mean of 10 months with naproxen. A dosage of $250 \mathrm{mg}$ twice daily produced sustained improvement in most of the standard clinical measurements. 28 patients complained of side effects, with a lower than expected incidence of gastrointestinal complaints and no drug-induced rash being recorded. 19 patients withdrew from the trial because of side effects, while a further 22 withdrew because the drug was ineffective. Naproxen is a useful drug for long-term use in patients with rheumatoid arthritis, including those who have proved intolerant of or experienced inadequate symptomatic relief from other nonsteriodal anti-inflammatory agents.
\end{abstract}

Naproxen (d-2(6'-methoxy-2'-napthyl)-proprionic acid) was introduced into clinical practice in the United Kingdom in September 1973. In a standard, double-blind, 8-week cross-over study comparing naproxen $500 \mathrm{mg} /$ day with aspirin $4 \mathrm{~g} /$ day in patients with rheumatoid arthritis the two drugs were found to be equally effective in controlling this disease as assessed by objective and subjective parameters (Hill and others, 1973, 1974). Naproxen was better tolerated, and in particular, was associated with less dyspepsia or evidence of gastrointestinal bleeding. Since such side effects are a major problem in the treatment of rheumatoid arthritis, this paper describes the use of naproxen for a mean of 10 months in 121 patients with rheumatoid arthritis, the majority of whom has proved intolerant of other nonsteroidal, anti-inflammatory (NSA) agents.

\section{Patients}

The 121 patients, 96 women and 25 men, from four centres, consisted of three groups. (i) 16 patients who after initial cross-over studies with aspirin agreed to take part in a longer trial. (ii) 91 patients who had proved intolerant of one or more standard NSA agents sufficient to cause their discontinuation. (iii) 14 patients who had experienced inadequate symptomatic relief from other NSA agents.

The mean age of the patients was 56.6 years (range 26-80 years). The mean duration of disease was $10 \cdot 1$ years (range 6 months-38 years). All were outpatients with active, classical or definite rheumatoid arthritis.

Those in groups (ii) and (iii) exhibited three of the follow- $\dot{\sigma}$ ing symptoms: 4 or more tender or painful joints, 4 or more joints with active synovitis, morning stiffness of more than 45 minutes' duration, and an erythrocyte $₹$ sedimentation rate (Westergren) $28 \mathrm{~mm} / 1 \mathrm{~h}$. However, $O$ most patients in group (i), although they had fulfilled these clinical criteria on admission to the 8-week cross- $\frac{7}{2}$ over study with naproxen $500 \mathrm{mg} /$ day and aspirin $4 \mathrm{~g}$ /day now had less active disease. All three groups were similar $N$ with respect to sex, age, and duration of disease.

\section{Method}

In general patients were assessed at $1,3,6$, and 12 months and thereafter at 6-monthly intervals, with additional 0 assessments on withdrawal from the study. Assessment $\frac{}{\Phi}$ was by the same observer at each centre, who used the $\stackrel{0}{?}$ same routine clinical measurements as in the initial ? cross-over studies with aspirin (Hill and others, 1974). The following were measured and recorded: functional 
class (graded 1-4); duration of morning stiffness (graded $0-7$ ); severity of pain at rest and on movement (graded 0-2); the number of painful joints during a full range of active, nonweight-bearing motion $(0-16)$; the number of tender and/or swollen proximal interphalangeal joints $(0-8)$; total proximal interphalangeal joint circumference for each hand; grip strength in both hands; and walking time for a distance of 50 feet.

The patient and physician also made five point, graded overall assessments of the severity of the current disease and of the change from the last visit. Routine biochemical, haematological, and urine tests were undertaken at each visit.

The patients were not asked specifically about possible listed side effects but were merely asked whether they had any problems or difficulties with the drug. Any complaint was discussed with the patient, and if it appeared to be drug related the association was classified as being definite or possible (Hill and others, 1974; Huskisson and Wojtulewski, 1974).

Naproxen $250 \mathrm{mg}$ was given twice daily, although an increase in dosage was permitted, while concomitant therapy with gold, corticosteroids, or antimalarials was continued unchanged throughout the study.

\section{Results}

CLINICAL

The mean treatment time ( \pm 1SD) was 10.41 months \pm 8.81 , with one patient completing 32 months of treatment. Clinical measurements have been compared with baseline values for each of the standard intervals up to 24 months, small numbers of patients making subsequent calculations invalid.

There were no significant differences in the results between any patient group. There were significant and maintained improvements in morning stiffness, the number of painful joints, the number of tender and/or swollen proximal interphalangeal joints, the mean proximal interphalangeal joint circumference for each hand, grip strength, and walking time (Table I). There were no changes in functional capacity while patients only showed a significant reduction over baseline values in pain at rest up to 6 months $(P<0.05)$ and in pain on movement up to 12 months $(P<0.001)$. As would be expected from the above, both patients and physicians recorded modest overall improvement at each assessment.

\section{LABOR ATORY}

No abnormal biochemical or urine results were recorded, nor were there significant changes in the ESR or haemoglobin values. In particular, there were no significant changes in the haemoglobin values in the patients in group (ii), those who had a past history of side effects, frequently indigestion, to other standard NSA agents.

\section{SIDE EFFECTS}

The number of patients complaining spontaneously of side effects and whether or not after discussion

Table II Side effects in groups $i, i i, i i i$

\begin{tabular}{|c|c|c|c|c|c|c|}
\hline \multirow[b]{2}{*}{ Side effect } & \multicolumn{3}{|c|}{ Drug related } & \multicolumn{3}{|c|}{ ? Drug related } \\
\hline & $\mathrm{i}$ & ii & iii & $\mathrm{i}$ & ii & iii \\
\hline Indigestion & 1 & 1 & & & 9 & 3 \\
\hline Nausea & & 2 & & & 2 & 2 \\
\hline Diarrhoea/ & & & & & & \\
\hline constipation & & 3 & & & 3 & 1 \\
\hline Anorexia & 1 & 2 & & & & \\
\hline Malaena & & 1 & & & & \\
\hline Tinnitis & & 2 & & & 2 & \\
\hline Sleeplessness & 2 & 2 & & 2 & 1 & \\
\hline Depression & & & & & 1 & \\
\hline Rash & & & & 1 & 1 & \\
\hline Sore mouth & & 1 & & & 1 & \\
\hline Other & & 10 & & 1 & 16 & 4 \\
\hline Tota & $\overline{4}$ & $\overline{24}$ & - & $\overline{4}$ & $\overrightarrow{36}$ & $\overrightarrow{10}$ \\
\hline ( $\%$ of patients) & (25) & (26) & & (25) & (40) & (71) \\
\hline
\end{tabular}

Table I Changes in clinical measurements 
between the patient and physician the effect was considered to be due to the drug are given in Table II. As expected, a higher percentage of patients from group (ii) with a past history of side effects had side effects to naproxen.

\section{PATIENT WITHDRAWALS}

Naproxen was withdrawn usually because of side effects or lack of clinical benefit in 46 patients (Table III). 38 of these were in group (ii), with 4 patients being withdrawn from both groups (i) and (iii). As expected all the withdrawals from group (iii) were because the patients found naproxen, like the other NSA agents they had tried, ineffective. Almost half the withdrawals from group (ii) were due to side effects.

Overall, 22 patients $(18.2 \%)$ were withdrawn because of lack of clinical benefit, $19(15.7 \%)$ because of side effects, and $5(4 \cdot 1 \%)$ for other reasons, including unrelated death due to cervical carcinoma, and rheumatoid vasculitis, disease in remission ( 2 cases), and a wish to try a different drug after 26 months of treatment.

Table III Withdrawals from trial

\begin{tabular}{|c|c|c|c|}
\hline \multirow[b]{2}{*}{ Reason for withdrawal } & \multicolumn{3}{|l|}{ Group } \\
\hline & $\begin{array}{l}\mathrm{i} \\
(\mathrm{n}=16)\end{array}$ & $\begin{array}{l}\text { ii } \\
(n=91)\end{array}$ & $\begin{array}{l}\text { iii } \\
(n=14)\end{array}$ \\
\hline Ineffective & 2 & 16 & 4 \\
\hline Side effects & 1 & 18 & - \\
\hline Other & 1 & 4 & - \\
\hline
\end{tabular}

DRUG DOSAGE AND REGIMENS

Naproxen was started in an initial dose of $250 \mathrm{mg}$ twice daily, and although changes were permitted to improve the clinical response, 96 patients were maintained on this regimen. In a further 10 patients the twice-daily regimen was maintained but the total daily dose was increased to $750 \mathrm{mg}$, the majority of patients preferring $500 \mathrm{mg}$ in the evening. Dosage was reduced to $125 \mathrm{mg}$ twice daily in one patient, while the remainder received $250 \mathrm{mg}$ three times per day. These final drug dosages represent a range of from 4 to $19 \mathrm{mg}$ naproxen/ $\mathrm{kg}$ body weight per day (mean 9.4).

\section{Discussion}

A number of chemically similar nonsteroid antiinflammatory agents have been introduced into clinical practice in the United Kingdom during the past 3 years and new products will appear shortly. The requirements of the Committee for the Safety of Medicines and the Pharmaceutical Companies Marketing Departments ensure that all such drugs will have been shown to be clinically effective, to be comparable in effect in short-term trials to full doses of aspirin, and to have few side effects. Such studies? will also have indicated an average optimum daily $\overrightarrow{\vec{F}}$ dose of the new drug. Almost all patients withrheumatoid arthritis, however well their disease is $\frac{\square}{\circ}$ controlled, show some clinical improvement during $\overline{\bar{c}}$. short-term clinical trials with active drugs, suggest- $\bar{\Phi}$ ing that frequent assessment and encouragement in 2 hospital clinics and supervision of drug taking are both beneficial. Thus, such studies do not necessarily $\vec{O}$ indicate the possible effect of the drug in extended $\overrightarrow{ }$ clinical usage. Further, short-term studies may alsow fail to show the true incidence of side effects to the@ new drug. Lastly, since most of these drugs are? introduced into clinical practice with a suggested w optimum (and frequently fixed) dosage which takes no account of differences in body weight and of $\overrightarrow{0}$ differences in the patient's absorption, metabolism,,$\infty$ and excretion of the drug, many patients may experience minimal or a declining clinical benefit if $\vec{\square}$ the chosen dose is too small.

This extended follow-up of naproxen in patients $\stackrel{\mathbb{D}}{7}$ with rheumatoid arthritis was undertaken to assess whether the initial standard drug dosage and regimen needed to be adjusted and whether the drug coftinued to show clinical benefit with a low incidente.? of side effects over a period of months with or occasional hospital assessment. Only patients with active disease were included in the study while a high proportion of the patients were either intolerant of or had found ineffective the commonly used $\stackrel{\odot}{\odot}$ drugs such as aspirin preparations and indomethacin. $\overrightarrow{\vec{P}}$ This selection of patients was deliberate since it is $\frac{3}{3}$ chiefly in these 'difficult to treat' patients that a change from the commonly used drugs is indicated. The treatment of mild cases who have shown good tolerance to existing drugs is likely to show encouraging but unhelpful results.

On the basis of a number of standard objective and subjective parameters the study shows that the $\mathrm{O}$ clinical benefit of naproxen in patients with rheuma-

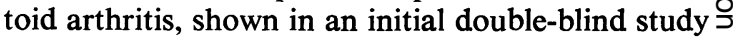
(Hill and others, 1974), continues for up to 32 months. Naproxen has a clear analgesic effect and on the basis of the duration of morning stiffness, the $N$ number of swollen and tender proximal interphalangeal joints, grip strength, and changes in proximal 0 interphalangeal joint circumference, probably the $\omega$ best test (Boardman and Hart, 1967), sustained antiinflammatory activity.

All patients were started on the recommended $\stackrel{D}{\mathbb{D}}$ dose of $250 \mathrm{mg}$ naproxen twice daily, changes in dosage and regimen being required in only $25{ }^{\circ}$ patients. Dosage ranged from 4 to $19 \mathrm{mg} / \mathrm{kg}$ body $\underset{\mathbb{D}}{\mathbb{D}}$ weight per day on this regimen, thus indicating that $\frac{?}{1}$ tailoring the dosage on the basis of body weight 
is not useful. A thrice-daily regimen was rarely necessary, confirming the 12-hour duration of action of the drug.

Forty-six of the 121 patients had to be withdrawn from the trial, although 5 withdrawals were for reasons unconnected with the drug therapy. 21 patients were withdrawn, the majority within the first 3 months of the study, because of lack of clinical benefit. All 4 withdrawals from group (iii) were because the patients found naproxen, like other NSA agents they had tried, ineffective. However, 16 of 91 patients (17.5\%) from group (ii) found the drug ineffective and required other treatment, often gold, penicillamine, or an increase in corticosteroid dosage. 19 patients were withdrawn, again mostly within the first 3 months of the study, because of side effects. All but one of these were from group (ii), those patients intolerant of other NSA agents. The good tolerance of naproxen confirms the findings of earlier trials and its withdrawal from only $19.8 \%$ of this difficult group of patients is considered satisfactory. As with most current trials of NSA agents patients were not asked to choose from a specific list of possible side effects but were simply asked, 'have you had any problems or difficulties with the drug?' (Huskisson and Wojtulewski, 1974). 28 complained of a range of side effects chiefly related to the gastrointestinal and central nervous systems, which were considered by both patients and physician to be due to naproxen, while a further 50 patients complained of a similar range of side effects not considered to be directly attributable to the drug. In neither instance was the usual high incidence of nausea and dyspepsia, recorded with other NSA agents, noted. Further, there were no proved instances of a naproxen-induced rash. The incidence of these side effects confirms the findings of the earlier, short-term trials (Hill and others, 1974) and shows that extended treatment with naproxen is not associated with a higher or increasing incidence of side effects.

Finally, despite occasional reports of severe gastrointestinal tract bleeding with naproxen (Hart, 1974; Matts, 1974), there is no evidence in this study from sequential haemoglobin values and a single report of malaena that this is a common side effect. Clearly the drug does cause some gastrointestinal tract blood loss (Hill and others, 1974; Halvorsen, Dotevall, and Sevelius, 1973), and with any widely used preparation there will inevitably be a small number of patients who have more serious, idiosyncratic bleeding episodes (Mowat, 1973). Other routine, haematological, biochemical, and urine testing did not show any abnormalities.

\section{References}

BOARDMAN, P. L., AND HART, F. D. (1967) Brit. med. J., 4, 264 (Clinical measurement of the anti-inflammatory effects of salicylates in rheumatoid arthritis)

Halvorsen, L., Dotevall, G., ANd Sevflius, H. (1973) Scand. J. Rheumatol., Suppl. 2,43 (Comparative effects of aspirin and Naproxen on gastric mucosa)

HART, F. D. (1974) Brit. med. J., 2, 51 (Naproxen (Naprosyn) and gastrointestinal haemorrhage)

Hill, H. F. H., Hill, A. G. S., Mowat, A. G., Ansell, B. M., Mathews, J. A., Seifert, M. H., Gumpel, J. M., AND Christie, G. A. (1973) Scand. J. Rheumatol., Suppl. 2, 176 (Multi-centre, double-blind cross-over trial comparing Naproxen and aspirin in rheumatoid arthritis)

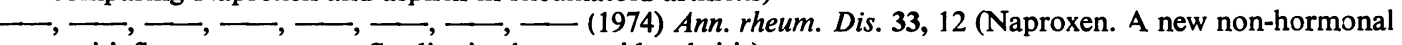
anti-inflammatory agent. Studies in rheumatoid arthritis)

Huskisson, E. C., AND WoJTulewski, J. A. (1974) Brit. med. J., 2, 698 (Measurement of side-effects of drugs)

MATTs, S. G. F. (1974) Brit. med. J., 2, 52 (Naproxen (Naprosyn) and gastrointestinal haemorrhage)

MowAT, A. G. (1973) 'Problems of treatment with currently available non-steroid, anti-inflammatory agents' in 'Naprosyn Symposium, London', ed. G. A. Christie, p. 27. Syntex, Maidenhead 